\title{
THE ENDOVENOUS LASER THERAPY FOR THE MANAGEMENT OF VARICOSE VEINS
}

\author{
Kaushal $P^{1^{*}}$, Shen $X S^{2}$
}

\section{Affiliation}

1. Resident, Department of General Surgery, School of Clinical Medicine, Inner Mongolia University for the Nationalities, Inner Mongolia, China

2. Professor, Department of General Surgery, Affiliated Hospital of Inner Mongolia University for the Nationalities, Inner Mongolia, China

\section{ARTICLE INFO}

Article History

Received : 15 April, 2018
Accepted $\quad$ : 23 July, 2018
Published : 31 August, 2018

(c) Authors retain copyright and grant the journal right of first publication with the work simultaneously licensed under Creative Commons Attribution License CC - BY 4.0 that allows others to share the work with an acknowledgment of the work's authorship and initial publication in this journal.

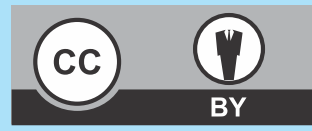

ORA 71

\section{DOI: http://dx.doi.org/10.3126/bjhs.v3i2.20941}

* Corresponding Author

Dr. Prashant Kaushal Resident

Department of General Surgery School of Clinical Medicine

Inner Mongolia University for the Nationalities 536 West Huo Lin He Street, Horqin District, Tongliao, Inner Mongolia, China

Email: prashant.neuro@gmail.com

ORCID: https://orcid.org/0000-0003-2652-4243

\section{Citation}

Kaushal P, Shen XS. The Endovenous Laser Therapy for the Management of Varicose Veins. BJHS 2018;3(2)6:437-442.

\section{ABSTRACT \\ Introduction}

Varicose veins of the lower limb are common condition affecting majority of people worldwide and has great effect on quality of life. The definitive therapy being surgery with stripping of the veins which is associated with surgical complications, prolong recovery time and significant recurrence. Endovenous laser therapy (EVLT) is a minimally invasive procedure which is widely used for the treatment of varicose veins with excellent results.

\section{Objective}

To evaluate the safety and efficacy of EVLT for the management of varicose veins.

\section{Methodology}

This was a prospective study of 40 patients who underwent endovenous laser therapy at the affiliated hospital of Inner Mongolia University for the Nationalities from October 2016 to September 2017. All patients with primary symptomatic varicose veins with sapheno-femoral incompetence or great saphenous vein (GSV) reflux were included in the study. The patient's information and data were recorded during the hospital stay in the proforma for EVLT with the informed consent. The variables used were mean operating time, intra-operative blood loss, duration of hospital stay, return to normal activity, complications and the recanalization. Following discharge, the patients were followed up to six months.

\section{Results}

Forty patients with unilateral varicose veins were treated with EVLT. There were 24 female and 16 male with mean age of 52 yrs and the majority of patients having symptoms for more than five years. The mean operative time and intra-operative blood loss were 80 minutes and $52 \mathrm{ml}$ respectively. The mean duration of hospital stay was 2.5 days with $90 \%$ patients returning to the normal activity in 10 days. Swelling and indurations were the most common complication in 10 patients followed by hypoesthesia in 8 , ecchymosis in 7 and skin burn in 4 patients.

\section{Conclusion}

EVLT seems to be safe and effective minimally invasive procedure with excellent clinical outcome in terms of lower postoperative pain, early return to normal activities and fewer complications. However large sample size with long follow up study should be conducted for evaluating long term benefits.

\section{KEYWORDS}

Endovenous laser therapy, great saphenous vein reflux, varicose veins. 


\section{INTRODUCTION}

Varicose veins are the tortuous, widened veins in the subcutaneous tissue of the leg. It is one of the most common benign vascular disease in the world which can affect up to 25 percent of women and 15 percent of men. ${ }^{1}$ In majority of the patients it is due to saphenofemoral incompetence and great saphenous vein (GSV) reflux leading to increase in venous pressure resulting in dilated, tortuous veins in the lower limbs which if left untreated can severely affect the quality of life. ${ }^{2}$ The ultimate goal of treatment is to eliminate the source of reflux in order to control symptoms and progression of the disease. In past conventional surgery was considered as the gold standard which involved saphenofemoral ligation, GSV stripping and phlebectomy of the residual varicosities which was associated with various drawbacks and procedure related complications.

Recently, minimally invasive endovenous techniques have been developed as alternatives to conventional surgery. Endovenous Laser Therapy (EVLT) is one of the most promising techniques which were first introduced in 1998 by Spanish phlebologist, Carlos Bone for the management of varicose veins. ${ }^{3}$ EVLT has better outcome than the conventional surgery in terms of reduced post-operative pain, post-intervention bleeding, hematoma along with decrease rate of wound infection, early recovery and return to normal life. ${ }^{4}$ Moreover studies have shown that EVLT has less recurrence rate due to reduced neovascularisation. ${ }^{4,5}$ The aim of this study is to evaluate the safety, efficacy and surgical outcome of EVLT which can be considered as an alternative to the conventional surgery for the management of varicose veins.

\section{METHODOLOGY}

This is a prospective study of 40 patients who underwent EVLT at the affiliated hospital of Inner Mongolia University for the Nationalities from October 2016 to September 2017. The study was approved by the Institutional Review Board of the university. All patients with primary symptomatic varicose veins with sapheno-femoral incompetence or great saphenous vein (GSV) reflux were included in the study. After thorough history and a complete physical examination, patients were scheduled for duplex scanning of the affected lower limbs to document the patency of the deep veins and evaluate the extent and severity of the reflux in the superficial venous system. The skin overlying the incompetent source of venous reflux was marked. The indication of treatment were patients preference; large varicose veins with cramp and ache, eczema, and ulceration. The patient's information and data were recorded during the hospital stay in the proforma for EVLT with the informed consent. Following discharge, the patients were followed up to six months. The variables recorded and analyzed were mean operating time, intra-operative blood loss, duration of hospital stay, return to normal activity, complications and the recanalization.

\section{Exclusion Criteria}

1. Patient with coagulopathy

2. Pregnant, breast feeding patients

3. Patient with recurrent varicose veins

4. Suspected or proven DVT

5. Previous history of venous surgery

\section{Operative technique}

All patients underwent EVLT in spinal anesthesia using an $810 \mathrm{~nm}$ diode laser (L.H.H Medical, Beijing, China) with 600 $\mu \mathrm{m}$ optical fiber. After proper sterilization and draping of the target limb, a 2-3 cm incision was performed in the groin to expose and ligate the great saphenous vein (GSV) and its tributaries at the saphenofemoral junction (SFJ). After ligation of the proximal GSV, the access to the distal part of GSV was achieved through a puncture with an $18 \mathrm{G}$ canula at the medial malleolus. On canulation, a J-tip 0.035 inch ultra smooth hydrophilic guide wire was inserted into the vein up to the SFJ. A 5F catheter was placed in to the GSV over the guide wire. The guide wire was removed and replaced with $600 \mu \mathrm{m}$ optical fiber connected to $810 \mathrm{~nm}$ diode laser with the laser tip positioned $1-2 \mathrm{~cm}$ below the SFJ and was confirmed by the red beam of light from the laser tip through the skin. After proper confirmation of the fiber tip, the laser energy was fired in pulse mode and the laser along with the catheter was slowly withdrawn at the rate of 3-5 $\mathrm{mm}$ per second. Manual compression was applied over the red aiming beam which could be visualized through the skin. The compression assists in better laser fiber and vessel endothelial contact leading to complete shrinkage and occlusion of the vein. A laser emission power of 16W, 14W and $12 \mathrm{~W}$ was maintained at thigh, knee and calf respectively. Finally the varicosities caused by tributaries of GSV were treated with multiple percutaneous introductions of laser fiber through an $18 \mathrm{G}$ needle.

The groin incision was closed and elastic bandage was applied for five days which was switched to compression stockings for six weeks. NSAIDs were prescribed routinely for postoperative pain. Early ambulation was advised and the patients were encouraged to resume normal activity as soon as possible. Majority of the patients were discharged on the second post operative day with further assessment after one week, one, three and six months. Follow up was aimed to assess symptomatic improvement, residual or recurrent varicose veins, post operative complications including pain, swelling, hypoesthesia, ecchymosis and burn. Doppler ultrasound was performed to document the recanalisation of the GSV. 

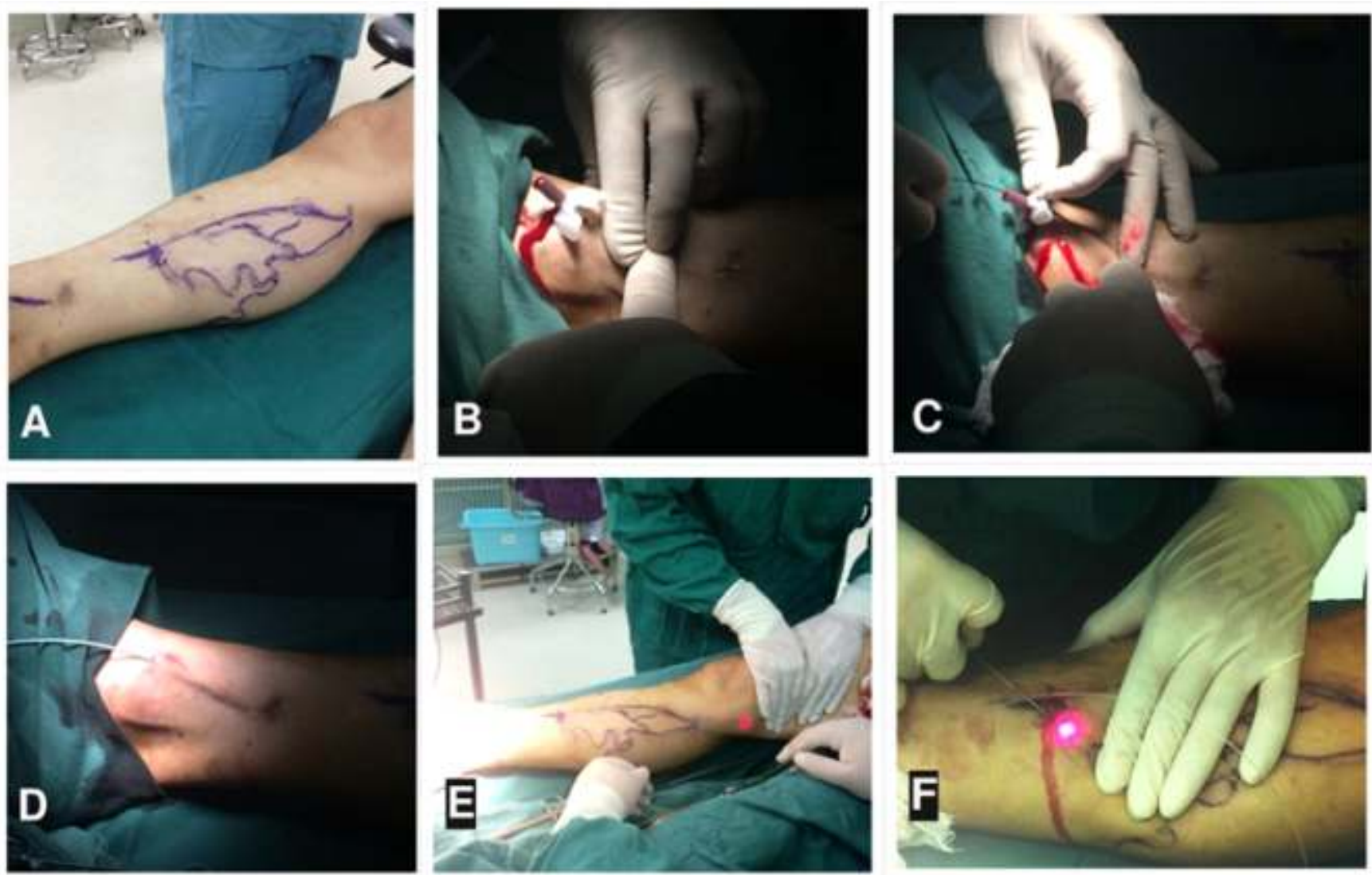

Figure 1: Operative Procedure of EVLT;

(A) Skin marking overlying the incompetent source of venous reflux with the help of duplex scan.

(B) Establishing the access to the distal part of GSV through puncture with a $18 \mathrm{G}$ canula at the medial malleolus;

(C) Insertion of a J-tip 0.035 inch ultra smooth hydrophilic guide wire into the vein up to the SFJ.

(D) Placement of $5 \mathrm{~F}$ catheter into the GSV over the guide wire;

(E) Guide wire removed and replaced with 600 $\mu$ moptical fiber, the laser energy fired.

(F) Multiple percutaneous introductions of laser fiber for the varicosities caused by the tributaries of GSV.

\section{RESULT}

Statistical data analysis was performed using Microsoft office Excel 2007 and IBM SPSS Statistics 20. Among forty patients treated with EVLT, there were 24 female (60\%) and 16 male (40\%) with mean age of 52 yrs and about $60 \%$ of patients having symptoms of varicose veins for more than five years. The commonest presentations were lower limb cramp, ache and swelling whereas two patients presented with venous leg ulcer. The mean operative time was 80 minutes with intra-operative blood loss of $<50 \mathrm{ml}$ in 33 patients (82.5\%) and $>50 \mathrm{ml}$ in 7 patients $(17.5 \%)$; the mean blood loss being $52 \mathrm{ml}$. Similarly 34 patients (85\%) were ambulated within 48 hours whereas 6 patients (15\%) were ambulated after 48 hours. The mean duration of hospital stay was 2.5 days with 36 patients (90\%) patients returning to the normal activity in ten days. Postoperative complications included swelling and indurations which was the most common complication in 10 patients (25\%) followed by hypoesthesia in $8(20 \%)$, ecchymosis in 7 $(17.5 \%)$ and skin burn in 4 patients $(10 \%)$. The procedure related complications were gradually subsided within one month after surgery. There was no incidence of deep vein thrombosis, pulmonary embolism, wound infection or hematoma. Doppler ultrasound was performed in all patients to monitor the recanalisation of the GSV. Short term recurrence was noted in one patient (2.5\%) within a month which was managed with repeat EVLT. Hence the overall success rate for GSV ablation was $97.5 \%$ at six months. There was minimal postoperative pain and the preoperative symptoms were resolved within a month.

$\begin{array}{lcc}\text { Table 1: Complications after EVLT } & \\ \text { Complications } & \text { No. of Limbs } & \text { Percentage\% } \\ \text { Swelling and Indurations } & 10 & 25 \% \\ \text { Hypoesthesia } & 8 & 20 \% \\ \text { Ecchymosis } & 7 & 17.5 \% \\ \text { Burn } & 4 & 10 \% \\ \text { Wound Infection } & 0 & 0 \% \\ \text { Hematoma } & 0 & 0 \% \\ \text { DVT } & 0 & 0 \% \\ \text { Pulmonary Embolism } & 0 & 0 \%\end{array}$




\section{DISCUSSION}

Varicose veins is a common medical condition in Western countries predominantly affecting women. ${ }^{1}$ However a study conducted by Evans et al in England concluded that about $40 \%$ of men and $32 \%$ of women were affected with varicose veins in the British population. ${ }^{6}$ It affects nearly 10 $40 \%$ of Chinese population and is one of the major vascular problem in the country. ${ }^{7}$ The incidence of varicose veins increases with age and is most commonly due to valvular incompetence of the SFJ and the GSV which leads to reflux of blood and increase in venous pressure resulting in dilated and tortuous veins of lower limb. The risk factors for the development are old age, female sex, positive family history and pregnancy precipitated by modern sedentary lifestyle, obesity and prolong standing. ${ }^{8}$ Varicose veins may be asymptomatic but many patients present with a wide range of symptoms based on the severity of insufficiency ranging from cramp, aches, heaviness, itching, edema, swelling, hyper pigmentation and sometimes venous leg ulcers. The commonest presentations in our series were lower limb cramp, ache and swelling with two patients presenting with venous leg ulcer. The condition is sometimes considered to be a cosmetic problem and given low priority for treatment leading to increased morbidity and cost of management.

The traditional surgical method of ligation of GSV and its tributaries at the SFJ and stripping of the GSV has been considered as the gold standard in the treatment of varicose veins. ${ }^{9}$ However, the recurrence rate of as high as $30-40 \%$ has been reported in the literature. ${ }^{10}$ Fischer et al. followed up 125 limbs after SFJ ligation and GSV stripping for 34 years and showed recurrence rate of $60 \% .{ }^{10}$ Dwerryhouse et al. documented recurrence in $29 \%$ of patients after ligation and stripping of the GSV while $71 \%$ after high ligation alone. ${ }^{11}$ Similar results of $18 \%$ recurrence has been reported by Sarin et al. after ligation and stripping while $45 \%$ recurrence rate after high ligation only. ${ }^{12}$ In our series, we had a short term recurrence rate of $2.5 \%$ with EVLT. Recurrence of varicose veins after ligation and stripping is thought to be due to revascularization at the SFJ, double saphenous vein system or incomplete procedure. ${ }^{10,11}$ Apart from recurrence, there have been numerous drawbacks of the conventional surgery which includes prolonged use of anesthesia, long surgical scar, increased hospital stay, wound infection, hematoma, and paresthesia.

However, during the last decade the conventional surgical method has been replaced by several minimal invasive techniques developed to treat the incompetent GSV, such as endovenous laser therapy (EVLT), radiofrequency ablation (RFA) and ultrasound guided foam sclerotherapy. ${ }^{13}$ These treatment methods aims to reduce risk, morbidity, and cost while leading to acceptable short and long term results. Among the minimal invasive procedures, the EVLT has been gaining popularities as it offers reduced postoperative pain, post intervention bleeding and perisaphenous vein hematoma along with decreased rate of wound infection and potentially shorter periods of absenteeism from work. In addition neovascularisation is significantly reduced which causes decreased incidence of varicose vein recurrence. ${ }^{4,5,7,13}$ The EVLT acts by heatinduced collagen shrinkage, followed by fibrotic sealing of the vein lumen. Hence, in order to destroy a vein with laser, the vein wall must absorb enough energy to result in generating so much heat as to damage its entire layer. We have been able to achieve excellent result using EVLT technique.

EVLT was first introduced by Carlos Bone in the year 1999 for the treatment of GSV insufficiency using a $810 \mathrm{~nm}$ diode laser. ${ }^{3}$ However in $2001 \mathrm{Min}$ et al. and Navarro et al. were the first to publish the case series suggesting EVLT might be successful in the treatment of large varicosities. ${ }^{4,14}$ Since then, multiple case series have been published with successful closure rate of 94-99\% with improvement in the appearance of superficial varicosities and relief of symptoms. ${ }^{15-17}$ The majority of published studies reports a success rate of about $100 \%$ at one week after the procedure however the success rate declines over time, but remains over $90 \%$ in a large number of case series. ${ }^{15-17}$ Timperman et al. in their series of EVLT showed that the vein occlusion is related to the amount of energy delivered to the vein wall; lower the energy given, higher the probability of reopening or nonocclusion of the vein. ${ }^{18}$ There may also be technical errors that can result in inadequate vein wall heating, such as the rapid withdrawal of the laser fiber or the insufficient vein emptying without direct contact of the laser fiber with the vein wall that may ultimately lead to reopening or nonocclusion of the vein.

Min et al. treated 499 limbs with EVLT using an $810 \mathrm{~nm}$ diode laser with $600 \mu \mathrm{m}$ fiber and followed up for 2 years. They achieved GSV occlusion rate of $98 \%$ and $93 \%$ at 1 month and 2 years respectively. ${ }^{17}$ Huang et al. from china had a $100 \%$ occlusion rate in $230 \mathrm{GSV}$ at 2 weeks after EVLT. ${ }^{19} \mathrm{~A}$ large single centre study conducted by Ravi et al. in United States on 1091 limbs treated with EVLT achieved an occlusion rate of $95 \%$ at 1 year follow up..$^{20}$ Similarly an Italian report by Agus et al. performed EVLT on 1076 limbs where they achieved successful occlusion of $97 \%$ at 3 years. ${ }^{16}$ Two studies from Germany by Proebstle et al. and Schwarz et al. who documented an occlusion rate of $96 \%$ and $100 \%$ at 3 months respectively. ${ }^{15,21}$ Almeida et al. from the United states also achieved similar occlusion rate of $92 \%$ at 500 days in 819 limbs with EVLT. ${ }^{22}$ Our results are comparable with the above series in achieving $97.5 \%$ occlusion rate in 40 patients at six months follow up. The clinical outcome of large studies on EVLT is illustrated in Table 2. 
Table 2: Clinical outcome of various studies on EVLT

\begin{tabular}{|c|c|c|c|c|}
\hline Author & Country & No. of limbs & Duration of follow up & Successful occlusion \\
\hline AuthorRavi et al. ${ }^{20}$ & USA & 1091 & 1 year & $95 \%$ \\
\hline Agus et al. ${ }^{16}$ & Italy & 1076 & 3 years & $97 \%$ \\
\hline Almeida et al. ${ }^{22}$ & USA & 819 & 500 days ( 1.4 years) & $92 \%$ \\
\hline Min et al. ${ }^{17}$ & USA & 499 & 2 years & $93.4 \%$ \\
\hline Schwarz et al. ${ }^{21}$ & Germany & 312 & 3 months & $100 \%$ \\
\hline Proebstleet al. ${ }^{15}$ & Germany & 282 & 3 months & $96 \%$ \\
\hline Huang et al. ${ }^{19}$ & China & 230 & 2 weeks & $100 \%$ \\
\hline Present Series & China & 40 & 6 months & $97.5 \%$ \\
\hline
\end{tabular}

The rate of venous recanalisation after EVLT is significantly less as compared to conventional surgery and may vary from 0 to $7 \%$ in various literatures. ${ }^{15,16,17,19,20,21,23}$ Some authors support that the recanalisation of a vein is unlikely if the vein remains occluded at 12 months. ${ }^{25}$ However, there have been reports of recanalisation reported at 2 and 3 years after EVLT. ${ }^{17,24}$ The majority of recurrences occur within the first 3 months. In our series, recanalisastion was noted in $2.5 \%$ which occurred within a month of EVLT. Similarly the duration of operative time for EVLT is short with a mean of 80 minutes in our series. Similar results have been reported by Chang et al. and Gerard et al. with a mean operative time of 122 and 60 minutes respectively. ${ }^{26,27}$

There have been many trials comparing the significance of EVLT with the conventional surgery. Caradice et al. carried out a study in 280 patients by dividing into two groups, one with EVLT and the other with conventional surgery. ${ }^{28}$ The complications were rare in both groups but the incidence of hematoma; infection and sensory disturbances were higher in the surgical group. Similarly the quality of life and return to normal activity was earlier with EVLT. ${ }^{28}$ Darwood et al. treated 80 limbs with EVLT and 34 limbs with conventional surgery. ${ }^{5}$ They achieved GSV reflux abolishment in $94 \%$ of limbs treated with EVLT as compared to $88 \%$ with surgical stripping and ligation at 3 months. Return to normal activity and work was also quicker with EVLT. ${ }^{5}$ Theivacumar et al. compared the recurrence and neovascularisation between EVLT and surgery. ${ }^{29}$ They achieved similar recurrence rate of $6.6 \%$ and $7 \%$ in both the group however, neovascularisation was noticed only in $1 \%$ with EVLT as ompared with $18 \%$ in the surgery group. However, Christensocn et al. reported more postoperative hematomas in the surgery group, but bruising was more common with EVLT. ${ }^{30}$ Postoperative pain and return to normal activity were similar between groups. Rasmussen et al. had similar results with no difference in recurrence and quality of life in both groups. ${ }^{31}$

Although EVLT may have reduced complications as compared to conventional surgery, it may be associated with specific side effects related to laser such as DVT, pulmonary embolism and skin burns. The likelihood of DVT in larger series is less than $1 \%{ }^{16,17,20}$ Proebstle et al reported DVT after EVLT in a patient with polycythemia vera. ${ }^{15}$ Similarly Schwarz et al. reported DVT in $1.2 \%$ (2 patients) and pulmonary embolism in $0.6 \%$ ( 1 patient) in their series of 312 patients treated with EVLT. ${ }^{21}$ There were no cases of DVT and pulmonary embolism in our series. Skin burns are another possible EVLT associated adverse event and may occur if the administered energy is high. None of the major case series reported skin burns however Liu et al. and Yang et al. reported skin burns in $10 \%$ and $10.2 \%$ respectively. ${ }^{7,32}$

We experienced superficial skin burn in $10 \%$ of our patients which is high in comparison to the major published series but comparable with the smaller series of EVLT. Ecchymosis was the present in $17.5 \%$ of our patient which was due to multiple micro perforations of the venous wall due to high temperature of laser. It has been reported in several studies during the early period after EVLT, with an incidence of 23.0-100\%, which is generally self limiting and resolves with a 2-3 weeks. ${ }^{3,4,14,23,26}$ Indurations along the length of the saphenous vein was the most common complication present in $25 \%$ of our patients which was self limiting and subsided in 3-4 weeks. Similar incidence of indurations has been reported in major series of EVLT ranging from 55-100 \%. ${ }^{7,14,15,19,23}$ About $20 \%$ of our patients experienced hypoesthesia of the affected limb which has also been documented in major series with $1-36.5 \%$ involvement., ${ }^{4,23}$ ${ }^{26}$ Other complications such as DVT, Pulmonary embolism, hematoma, wound infection, and phlebitis were not encountered in our study.

These studies suggest that improvements in disease specific quality of life and patient satisfaction are similar for surgery and EVLT however return to normal activity and work in most of the studies occurs earlier after EVLT. In addition, EVLT in expert hands seems to be a less time consuming procedure with rare major complications and limited procedure related disturbances such as postoperative pain or ecchymosis, indurations, hypoesthesia, phlebitis which in most cases are self limiting.

\section{CONCLUSION}

EVLT for varicose veins is a safe, feasible and efficient minimally invasive technique which can replace the conventional surgery as it has shown excellent results without any major complications. However large sample size with long follow up study should be conducted for assessing the long term benefits. 


\section{RECOMMENDATION}

It is recommended that EVLT should be widely performed as an alternative to the conventional surgery. It is a safe and easy procedure with minimal visible scar and excellent outcome in short period of time.

\section{LIMITATIONS}

The limitations of our study include small sample size and short follow up.

\section{REFERENCES}

1. Callam MJ. Epidemiology of varicose veins. Br J Surg. 1994; 81: 167-173. PMID: 8156326

2. Labropoulos N, Leon M, Nicolaides AN, GiannoukasAD,Volteas N, Chan P. Superficial venous insufficiency: correlation of anatomic extent of reflux with clinical symptoms and signs. J Vasc Surg. 1994; 20: 953-958. PMID:799019

3. Boné $\mathrm{C}$. Tratamiento endoluminal de las varices con laser de diodo: studio preliminary. Rev PatolVasc. 1999; 5:35-46.

4. Min RJ, Zimmet, SE, Isaacs, M, Forrestal M. Endovenous laser treatment of the incompetnt greater saphenous vein. J VasclntervRadiol. 2001;2:1167-1171. PMID: 11585882

5. Darwood RJ, Theivacumar N, Dellagrammaticas D, Mavor AID, Gough MJ. Randomized clinical trial comparing endovenous laser ablation with surgery for the treatment of primary great saphenous veins. Br J Surg. 2008; 95: 294-301. PMID: 18844280

6. Evans C, Fowkes FG, Ruckley CV, Lee A. Prevalence ofvaricose veins and chronic venous insufficiency in men and women in the general population: Edinburgh Vein Study. JEpidemiol Community Health. 1999; 53: 149-153. PMID: 10396491

7. Liu JJ, Fan LH, Xu DC, Li X, Dong ZH, Fu WG. The endovenous laser treatment for patients with varicose veins. Pak J Med Sci. 2016; 32(1):55-58. PMID: 27022345

8. Lee AJ, Evans CJ, Allan PL, Ruckley CV, Fowkes FG. Lifestyle factors and the risk of varicose veins: Edinburgh vein study. J ClinEpidemiol 2003;56(2):171-9. PMID: 12654412

9. Rivlin S. The surgical cure of primary varicose veins. Br J Surg 1975;62:913-7. PMID: 1191955

10. Fischer R, Linde N, Duff C, Jeanneret C, Chandler JG, Seeber P. Late recurrent saphenofemoral junction reflux after ligation and stripping of the greater saphenous vein. J Vasc Surg. 2001; 34:23640. PMID: 11496274

11. Dwerryhouse S, Davies B, Harradine K, Earnshaw JJ. Stripping the long saphenous vein reduces the rate of reoperation for recurrent varicose veins: five-year results of a randomized trial. J Vasc Surg. 1999;29:589-92. PMID: 10194484

12. Sarin S, Scurr JH, Coleridge Smith PD. Assessment of stripping of the long saphenous vein in the treatment of primary varicose veins. Br J Surg. 1992; 79:889-93.PMID: 1422747

13. Manfrini S, Gasbarro V, Danielsson G, et al. Endovenous management of saphenous vein reflux. JVasc Surg. 2000; 32:330-42. PMID: 10917994

14. Navarro L, Min RJ, Bone C. Endovenous laser: a new minimally invasive method of treatment for varicose veins - preliminary observations using an 810 nm diodelaser. Dermatol Surg. 2001; 27:117-122. PMID: 11207682

15. Proebstle TM, Moehler T, Gul D, Herdemann S. Endovenous treatment of the great saphenous vein using a $1320 \mathrm{~nm} \mathrm{Nd:} \mathrm{YAG} \mathrm{laser} \mathrm{causes}$ fewer side effects than using a 940nm diode laser. Dermatol Surg. 2005;31:1678-83. PMID: 16336887

16. Agus GB, ManciniS, Magi G, IEWG. The first 1000 cases of Italian Endovenous -laser working group: rationale and long - term outcomes for the 1999-2003 period. IntAngiol. 2006;25:209-15. PMID: 16763541

17. Min RJ, Khilnani N, Zimmet SE. Endovenous laser treatment of saphenous vein reflux: long-term results. J VasclntervRadiol. 2003;14:991-996. PMID: 12902556

\section{ACKNOWLEDGEMENT}

We would like to acknowledge all the patients who were enrolled in this study.

\section{CONFLICT OF INTEREST}

None

\section{FINANCIAL DISCLOSURE \\ None}

18. Timperman PE, Sichlau M, Ryu RK. Greater energy delivery improves treatment success of endovenous laser treatment of incompetent saphenous veins. J VascIntervRadiol. 2004;15:1061-3. PMID: 15466791

19. HuangY, Jiang M, Li W, Lu X, Huang X, Lu M. Endovenous laser treatment combined with a surgical strategy for treatment of venous insufficiency in lower extremity: a report of 208 cases. J Vas Surg. 2005;42:494-501. PMID: 16171594

20. Ravi R, Rodriguez-lopez JA, Trayler EA, Barrett DA, Ramaiah V, Diethrich EB. Endovenous ablation of incompetent saphenous veins: a large single-center experience. J Endovasc Ther. 2006; 13: 244-248. PMID: 16643080

21. Schwarz T, Hodenberg EV, Furtwängler C, Rastan A, Zeller T, Neumann FJ. Endovenous laser ablation of varicose veins with the 1470-nm diode laser. Journal of Vascular Surgery 2010; 51: 1474-78. PMID: 20347542

22. Almeida JI. Raines JK. Radiofrequency ablation and laser ablation in the treatment of varicose veins. Ann Vasc Surg. 2006;20:547-52. PMID: 16791452

23. Proebstle TM, Gul D, Lehr HA, Kargl A, Knop J. Infrequent early recanalization of greater saphenous vein after endovenous laser treatment. J VascSurg 2003; 38:511-6. PMID: 12947269

24. Proebstle TM. Recanalization of the great saphenous vein (GSV) can be observed at 2 and 3 years after endovenous laser treatment. In: ACP 19th Annual Conference 2005. San Francisco: California

25. Ash J, Moore C. Laser treatment of varicose veins: order out of chaos. SeminVascSurg 2010; 23:101-6. PMID: 20685564

26. Chang C-J, Chua J-J. Endovenous laser photocoagulation (EVLP) for varicose veins. Lasers Surg Med. 2002; 31:257-262. PMID: 12355571

27. Gerard J-L, Desgranges P, Becquemin J-P, Desse H, Melliere D. Feasibility of ambulatory endovenous laser for the treatment of greater saphenous varicose veins: one-month outcome in a series of 20 outpatients. J Mal Vasc. 2002; 27: 222-225. PMID: 12457128

28. Carradice D, Mekako Al, Mazari FAK, Samuel N, Hatfield J, Chetter IC. Randomized clinical trial of endovenous laser ablation compared with conventional surgery for great saphenous varicose veins. Br J Surg. 2011;98:501-10. PMID: 21283981

29. Theivacumar NS, Darwood R, Gough MJ. Neovascularisation and recurrence 2 years after varicose vein treatment for sapheno-femoral and great saphenous vein reflux: a comparison of surgery and endovenous laser ablation. Eur J Vasc Endovasc Surg. 2009; 38:203-7. PMID:19524460

30. Christenson JT, Gueddi S, Gemayel G, Bounameaux H. Prospective randomized trial comparing endovenous laser ablation and surgery for treatment of primary great saphenous varicose veins with a 2 year follow up. J Vasc Surg. 2010;52(5):1234-41. PMID: 20801608

31. Rasmussen LH, Bjoern L, Lawaetz M, Lawaetz A, Blemings A, Eköf B. Randomised clinical trial comparing endovenous laser ablation with stripping of the great saphenous vein: clinical outcome and recurrence after 2 years. Eur J Vasc Endovasc Surg. 2010; 39:630-5. PMID: 20064730

32. Yang L, Wang XP , Su WJ, Zhang Y, Wang Y. Randomized Clinical Trial of Endovenous Microwave Ablation Combined with High Ligation Versus Conventional Surgery for Varicose Veins. European Journal of Vascular and Endovascular Surgery. 2013; 46 (4): 473-479. PMID: 23911734 